\title{
Immunohistochemical Localization of Endogenous IAA in Peach (Prunus persica L.) Fruit during Development
}

\author{
Wei Zhang ${ }^{1}$, Yang $\mathrm{Li}^{1}$, Mengya Shi ${ }^{1}$, Hao Hu${ }^{1}$, Baoguang Hua ${ }^{2}$, Aizhen Yang ${ }^{2}$, and Yueping Liu ${ }^{2 *}$ \\ ${ }^{1}$ College of Plant Science and Technology, Beijing University of Agriculture, China \\ ${ }^{2}$ College of Biological Science and Engineering, Beijing University of Agriculture, China
}

\begin{abstract}
Peach (Prunus persica L.) is a model species for stone fruit studies within the Rosaceae family. Auxin plays an important role in the development of peach fruit. To reveal the distribution of auxin in the tissues of peach fruit, immunohistochemical localization of IAA was carried out in the seed, mesocarp, and endocarp in developing peach fruit using an anti-indole-3-acetic acid (anti-IAA) monoclonal antibody. A strong IAA signal was observed throughout the outer and inner integument during peach fruit development, and the distribution was zonal. The IAA signal was mainly focused in mucilage layers in the outer integument. The outer integument may function to produce or store IAA in the seed; a strong IAA signal was detected in the cells around the vascular tissue, whereas a weak IAA signal was located in the vascular tissues. In the mesocarp, the cells around the vascular bundle tissue gave rise to an IAA signal that increased in the late phase of fruit growth, which coincided with a significant increase in fruit growth. The distribution of IAA, however, was changed when fruit was treated with auxin transport inhibitors NPA (1-N-naphthylphthalamic acid) or TIBA (2, 3, 5-triiodobenzoic acid); in mesocarp tissues, an IAA signal was detected mainly in vessels of the treated fruit. During the critical period of endocarp lignification, the vessel lignification process was negatively correlated with IAA signal. The present results confirmed that the distribution of IAA was different in various tissues of peach fruit according to the developmental stage. This research provides cytological data for further study of the regulatory mechanism of auxin in peach fruit.
\end{abstract}

Additional key words: Endocarp, Mesocarp, NPA, Outer and inner integument, TIBA

\section{Introduction}

The phytohormone auxin plays an important role in the regulation of many physiological processes of plant growth and development (Kalluri et al., 2011; Petrášek et al., 2011). In fruit development, great progress has been made toward understanding the regulatory mechanism of auxin on climacteric fruit, although the majority of research has focused on tomato (Solanum lycopersicum) (Molesini et al., 2009; Wang et al., 2005; Goetz et al., 2007; Mounet et al, 2009). Strawberry (Fragaria ananassa), which is widely used as a research model to study nonclimacteric fruits, has also been associated with auxin-induced ripening, and previous studies focused on the genes related to auxin signal transduction and in situ distribution of auxin (Liu et al., 2011; Hou and Huang, 2005).

Over the past few decades, peach (Prunus persica L.) has become one of the model species in the Rosaceae family (Verde et al., 2013). Ethylene and auxin have been regarded as the main phytohormone regulators of peach ripening (Trainotti et al., 2007). This study demonstrates that auxin plays a role in ripening peaches and interacts with ethylene during this process. The transcriptomics approach used in this work confirms that many genes related to the auxin signal transduction pathway are expressed in the pulp. Another study demonstrated that the auxin transport carriers of the PIN1 gene were expressed in the ripening process of peach fruit (Paponov et al., 2005). Torrigiani showed

\footnotetext{
*Comesponding author: liuyueping@bua.edu.cn

※ Received 22 May 2014; Revised 9 December 2014; Accepted 21 December 2014. We gratefully acknowledge the National Science Foundation (31101526) and Beijing Teachers Training Centers for Higher Education (067135300100) for funding this study. 
that jasmonic acid and spermine could affect fruit ripening and were related with ethylene and auxin (Torrigiani et al., 2012). Auxin is an important molecule both in early and late development (Bonghi et al, 2011), but the signal generating sites and transport pathway of auxin are poorly understood at present.

In order to understand the role and mechanism of auxin, we must primarily reveal its distribution in plant tissues. Immunohistochemical localization of endogenous indole3-acetic acid (IAA) has been applied to sunflower embryos (Thomas et al, 2002), Arabidopsis thaliana seedlings (Sieburth, 1999), tobacco zygote and embryo (Chen et al., 2010), and poplar rhizogenesis (Dong et al., 2012). Hou and Huang (2004) confirmed that an IAA signal was present in the vascular tissue of strawberry. In the earlier phase of fruit development, the IAA signal was mainly localized in the phloem, while at the late stage, the signal appeared in the xylem and gradually increased with strawberry fruit development. In the achene, the IAA signal was mainly distributed in the developing embryos and in the tissues around them. The distribution of endogenous IAA and its role in the regulatory mechanism of peach fruit development are unknown.

Embryo development was closely monitored with peach fruit growth. In the early stage of fruit development, a variety of hormones were involved in the cross-talk, and auxin may play a direct role in the signal transduction (Bonghi et al., 2011). In order to explore the source of IAA and observe its spatial distribution and dynamic changes, the immunohistochemical localization of IAA was carried out in different tissues of peach fruits. Additionally, the study aimed to understand the effect of exogenous auxin transport inhibitors on the distribution of IAA and to understand the possible sites where IAA might be produced.

\section{Materials and Methods}

\section{Plant materials and growth conditions}

Three neighboring peach trees (P. persica L. cv. Luwangxian) located in the experimental orchard of Beijing University of Agriculture (Changping District, Beijing, China) were the source of fruits. Three peaches, with no symptoms of pests and diseases, were harvested from each tree at 16, 28, $36,44,51,60,71,81,91$, and 98 days after full bloom (DAFB) in 2012. At 60 DAFB, the carpopodium of 10 fruits were treated with $50 \mu \mathrm{mol} \cdot \mathrm{L}^{-1} \mathrm{NPA}$ (naphthylphthalamic acid, NPA) or $50 \mu \mathrm{mol} \cdot \mathrm{L}^{-1}$ TIBA $(2,3,5$-Triiodobenzoic acid, TIBA) in vivo, the treatment with distilled water was used as control. The following steps were the treatment procedure. Firstly, carpogonium was rinsed with distilled water and its bark tissue was rubbed gently by forceps to remove them off. Then a piece of cotton soaked with NPA, TIBA reagent or distilled water was wrapped around the treated carpogonium, which was sealed with parafilm to avoid solution evaporation. Three days later, the treated fruits were sampled for a further study.

\section{Quantitative analysis of IAA}

The endogenous IAA content was analyzed according to the description of Liu (2013). The mesocarp, endocarp and seed of peach fruit were ground in liquid nitrogen separately, and one $\mathrm{g}$ of ground samples were extracted overnight at $4^{\circ} \mathrm{C}$ in $80 \%$ methanol with sodium diethyldithiocarbamate as an antioxidant. An stable isotope-labeled ${ }^{13} \mathrm{C}_{6}$-IAA $\left({ }^{13} \mathrm{C}_{6}\right.$-IAA were donated by Professor Aloys Hüttermann, University of Göttingen, Germany) were added as internal standards. The sample was purified further with 3-cc Oasis anion MCX SPE (Waters, USA). The eluted solution was dried under vacuum, dissolved in $50 \mu \mathrm{L}$ of HPLC initial mobile phase, and filtered through a $0.25-\mu \mathrm{m}$ filter $(4 \mathrm{~mm}$ in diameter). Ten microliters of sample solution was injected into the HPLC-MSn system (ESI). The separation of mixed compound was performed by Surveyor LC pump (Thermo Finnigan, Waltham, MA, USA $)$ and C18 column $(2.1 \times 150$ $\mathrm{mm}, 3.5 \mu \mathrm{m}$; Agilent, Santa Clara, CA, USA). An ion trap mass spectrometer (LCQ DECA XP MAX, Thermo-Finnigan, USA) coupled to an ESI source (Thermo Finnigan, USA) was used to identify the target compounds. The data were analyzed by Xcalibur 2.1 (Thermo Finnigan, USA). Each analysis was performed in triplicate.

\section{Sample embedding}

Harvested fruits were separated into seed, endocarp, and mesocarp quickly. Along the ventral suture, the mesocarp and endocarp were cut into approximately $0.05 \mathrm{~cm}^{3}$ blocks. Seeds were slit on one side of the raphe at the early development; after $60 \mathrm{DAFB}$, seeds were divided into three parts - proximal, medial and distal parts - to be used as embedding samples. All excised samples were pre-fixed immediately in $2 \%(\mathrm{w} / \mathrm{v})$ aqueous solution of 1-ethyl-3 (3-dimethyl-aminopropyl)-carbodiimide hydrochloride (EDAC, Sigma, USA) for $1 \mathrm{~h}$, then vacuumed and washed three times with $0.1 \mathrm{~mol} \cdot \mathrm{L}^{-1}$ phosphate-buffered saline (PBS, $\mathrm{pH}$ 7.2). After washing, the samples were post-fixed overnight in a solution containing $4 \%$ paraformaldehyde and $2.5 \%$ glutaraldehyde at $4^{\circ} \mathrm{C}$, dehydrated with n-butanol and ethanol, embedded in paraffin, and sectioned into $10 \mu \mathrm{m}$ slices. The slides were spread with polylysine before the 
fixing of the sections. Dried sections were deparaffinized with xylene and hydrated in an ethanol-water series.

\section{Immunostaining}

The procedure for the immunolocalization of IAA was performed as described by Hou and Huang (2005) with some modifications. Slides were incubated in a blocking solution $\left(3 \% \mathrm{H}_{2} \mathrm{O}_{2}\right)$ and washed briefly with a PBS solution. Antigen was restored with $0.01 \mathrm{~mol} \cdot \mathrm{L}^{-1}$ citrate buffer. After washed with PBS, the slides were immersed in normal goat serum for blocking, and then washed briefly with the PBS solution. A drop of $100 \mu \mathrm{L}$ primary IAA antibodies (Bioss, China) was added to each slide before the inner membrane was covered with plastic gloves and incubated overnight at $4^{\circ} \mathrm{C}$. The slides were washed vigorously with the PBS solution. Subsequently, the slides were incubated overnight with phycoerythrin (PE)-Cy3-labeled goat antimouse IgG (Bioss, China) at room temperature. After washed with PBS, the slides were stained with the 4, 6-diamidino2-phenylindole (DAPI) solution, fixed by anti-quenching fluorescent mounting medium, then observed and photographed by Olympus BX51-400X microscope (Olympus, Japan). Analysis was done using Motic Images Plus 2.0 software (Motic, China).

Two negative controls were used to verify the specificity of the antibody. One omitted the primary IAA antibody to test the non-specificity of IgG, while the other substituted non-immune goat serum for the IAA antibody to test the specificity of antibody. All other procedures were implemented as usual.

\section{Detection of lignin deposition}

A phloroglucinol-HCl reagent was used to stain tissues of different developmental peach fruit (Abeles and Biles, 1991). The fruit was cross-sectioned. After the reagent treatment, the stereomicroscope was used to observe the lignin deposition.

\section{Results}

\section{Growth curve of peach fruit}

The weight and diameter of growing fruits were monitored from 16 to 98 DAFB. Both parameters were characterized by three fruit growth stages: S1, S2, and S3 (Fig. 1). The first phase, rapid growth, was started from 16 DAFB to 44 DAFB, and the primary characteristic of this stage was the intensive equatorial growth. The stage from 44 DAFB to 71 DAFB was the hardening period, including a slow growth rate. The second fast-growth period was started from 71 DAFB to 98 DAFB, during which the diameter and fruit weight increased rapidly.

\section{IAA levels in different tissues of peach fruit}

The levels of IAA in mesocarp, endocarp and seed were assayed by HPLC-MS (Fig. 2). The level of IAA in seed was much higher than that in mesocarp and endocarp. There was no obvious difference between mesocarp and endocarp, in which tissues the level of IAA was little related with the development stage. After $60 \mathrm{DAFB}$, the level of IAA in seed was increased rapidly, reaching to a maximum at 71 DAFB.

Immunohistochemical location of IAA in various fruit tissues at different development stages

The immunolocalization assay was used to investigate the endogenous IAA distribution in various tissues of peach

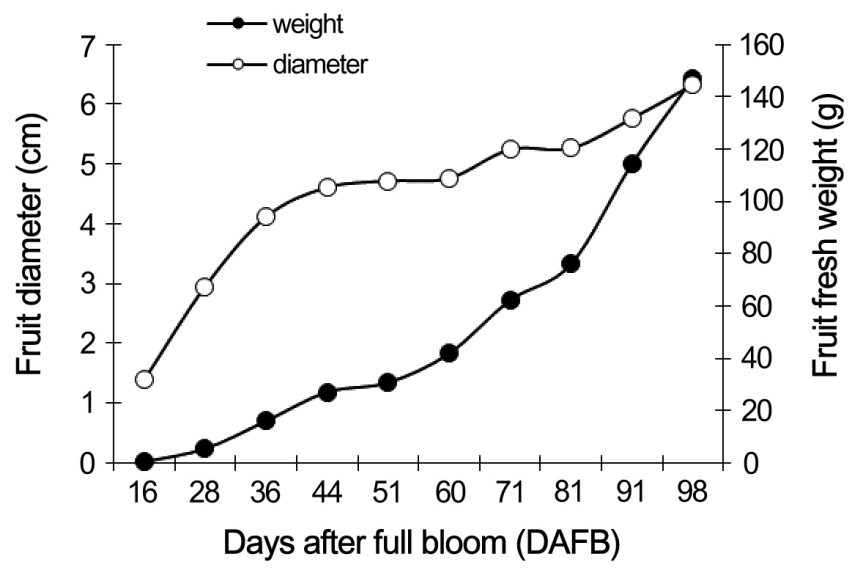

Fig. 1. Growth curve of peach ('Luwangxian') fruit.

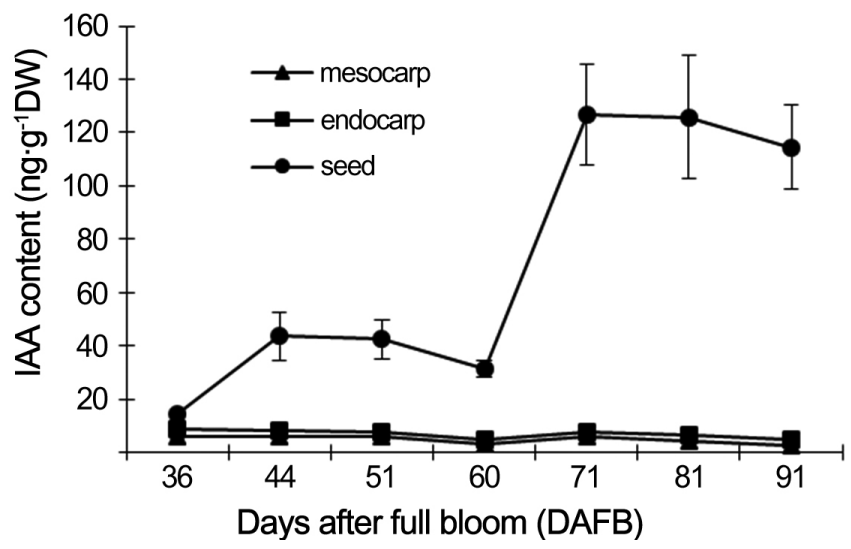

Fig. 2. Changes in IAA content in different tissues of peach ('Luwangxian') fruit. Values are means \pm SE $(n=3)$. 
fruit during development. The results are shown in Figure 3-6 in which the green fluorescent color reflects the cell position stained by DAPI dye, and the yellow fluorescent color is the IAA immunolocalization signal reflecting the level and distribution of endogenous IAA.

\section{IAA distribution in seeds}

Histological observations of the seed are shown in Figure
3. A strong IAA signal could be detected during the development of seed. In the longitudinal sections (Figs. 3a, e, f, $h$, i), a layer of inner integument cells were relatively dense, and the distribution of the IAA signal was banded in these cells. It was interesting to see that outer integument cells were full of IAA signal during fruit development, with some of the mucilage cells having a strong IAA signal (Figs. 3d, $\mathrm{e}, \mathrm{f}, \mathrm{h}, \mathrm{i})$. The function of these cells has remained unclear,
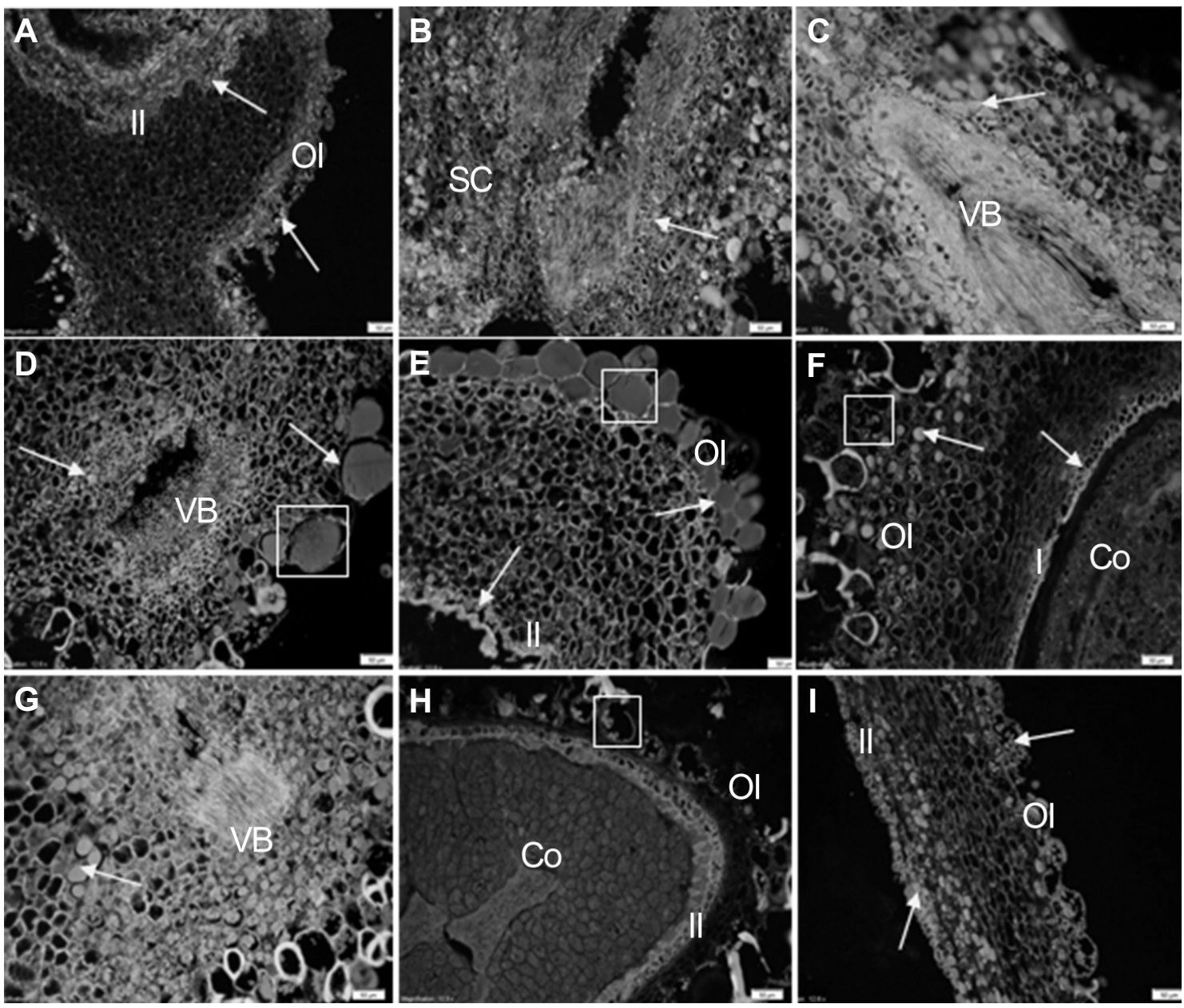

Fig. 3. Immunohistochemical localization of IAA in seed coat of peach ('Luwangxian') fruit during development. (a) Longitudinal section of the proximal part of seed in peach fruit sampled at 28 DAFB. IAA was detected in outer integument (OI) and inner integument (II) (arrows); (b, c) Transverse sections of the proximal part of seeds at 36 and 51 DAFB, respectively. Some of the cells had IAA signal throughout, and the vascular bundle (VB) could be clearly detected; (d) Some mucilage cells (rectangle boxes) in the distal part of the seed were bigger and had IAA signal throughout at 60 DAFB. (e) More IAA signal was detected in the outer integument and inner integument at the distal part of seed at 71 DAFB, some mucilage cells (rectangle boxes) with IAA signal throughout were detected. (f) Longitudinal sections of the proximal part of seed at 81 DAFB. The distribution of IAA was banded in the seed coat, but the signal was a little weaker compared with Fig. e. (g) Transverse sections of the proximal part of seed at 91 DAFB. Some of the cells around the vascular tissue had IAA signal throughout. (h) Longitudinal sections of the proximal part of seed at 98 DAFB, weak IAA signal were detected in the seed coat. (i) Longitudinal sections of the distal part of seed at 98 DAFB. Some mucilage cells in the outer integument of the seed had IAA signal throughout (rectangle boxes). There were more layers of cells with IAA signal throughout in the distal part of the seed at this stage. Co $=$ cotyledon. Arrows indicate examples of the immune signal of IAA. Bars $=50 \mu \mathrm{m}$. 
and although we did not observe direct evidence confirming their function whether they synthesize or store IAA, the presence of IAA in these cells was obvious. There was little IAA signal detected in tissues between the outer and inner integument. A strong IAA signal was detected in the seed coat in the transverse sections (Figs. 3b, c, d, g). In different development periods, there were no significant differences in IAA intensity. Vascular tissues contained no IAA signal, but strong IAA signals were detected in the layer of cells surrounding the vascular tissues (Figs. 3c, $\mathrm{d}$, g). Little IAA signal was detected in cotyledon on the proximal side as the fruit was developing (Figs. 3f, h). The results of Figure 3 indicated that the IAA distribution
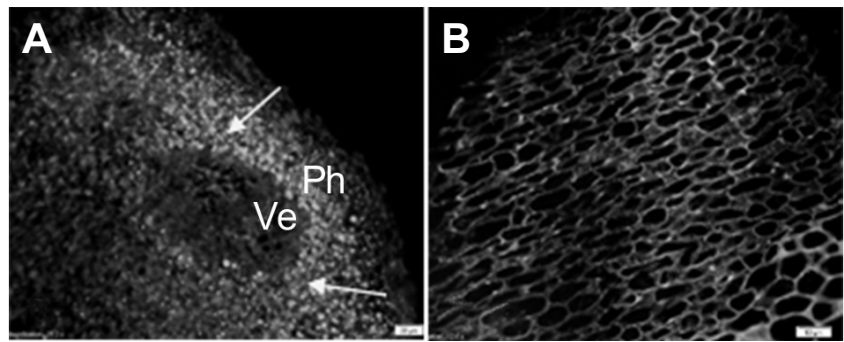

Fig. 4. Immunohistochemical localization of IAA in the endocarp of peach ('Luwangxian') fruit during development. (a) Strong IAA signals were distributed in the phloem (Ph) surrounding the vessel (Ve) tissue in the endocarp at 28 DAFB. (b) There was little IAA signal in the endocarp at 51 DAFB. Arrows indicate examples of the immune signal of IAA. Bars $=20$ $\mu \mathrm{m}$ (a) and $50 \mu \mathrm{m}(\mathrm{b})$. in the seed was characterized by the spatial specificity.

\section{IAA distribution in endocarp and mesocarp}

The distribution of IAA in the endocarp was analyzed before the tissue was lignified. At 28 DAFB, the endocarp cells were dense. A strong signal covering the entire cell was observed in the phloem surrounding the vessel tissue (Fig. 4a). Weak IAA signals were detected in endocarp cells at 51 DAFB (Fig. 4b).

The lignin deposition in the endocarp was observed via phloroglucinol-HCl staining (Fig. 5). At 71 DAFB, the endocarp was lignified entirely, except for the vascular tissue (Fig.
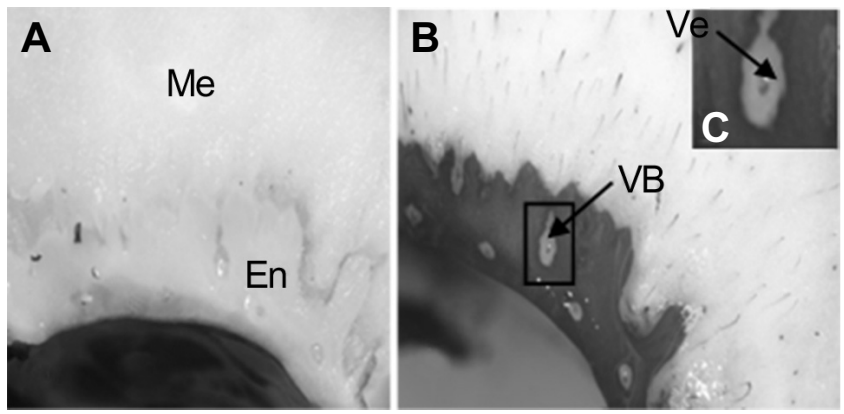

Fig. 5. Lignin deposition in peach ('Luwangxian') fruit at 71 DAFB. (a) The dissected fruit before staining showing endocarp (En) and mesocarp (Me). (b) The dissected fruit were incubated with phloroglucinol-HCl, which stains deposited lignin; the vascular bundles (VB) were not stained. (c) Detail of the boxed area in (b). The vessel (Ve) was stained.
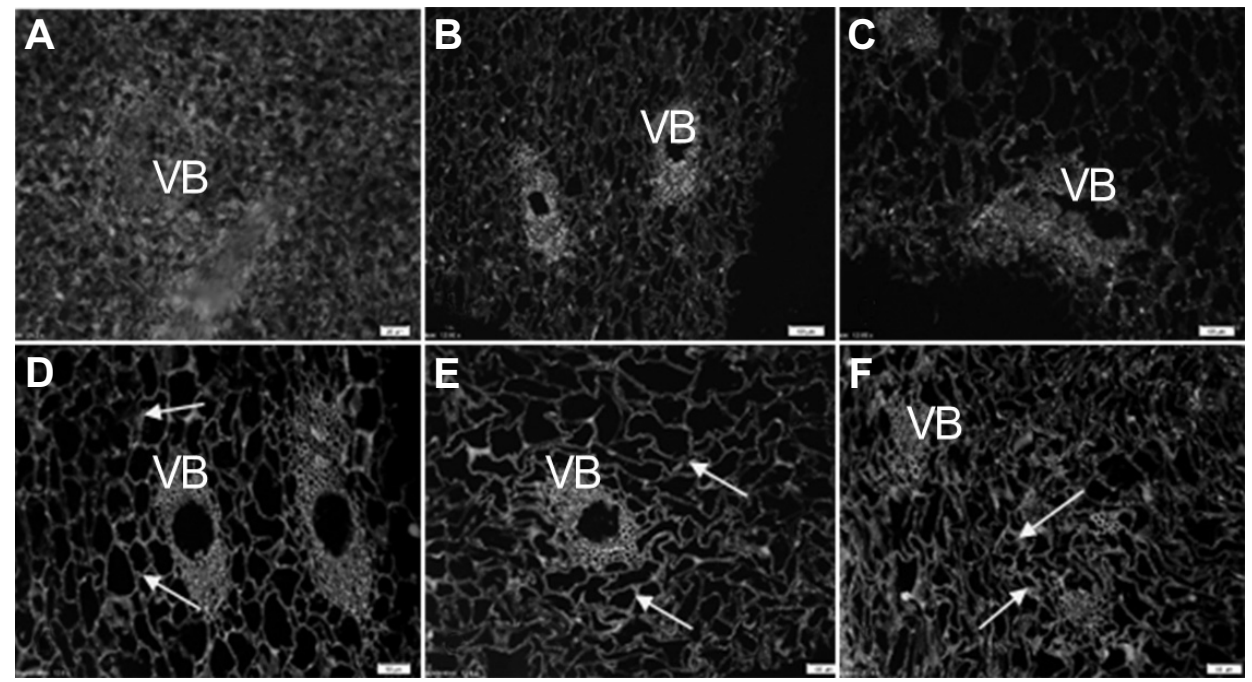

Fig. 6. Immunohistochemical localization of IAA in the mesocarp of peach ('Luwangxian') fruit during development. (a, b, c) Weak signals were distributed in mesocarp before 51 DAFB. (d, e, f) Slightly stronger IAA signal was located in the mesocarp cells around the vascular bundle (VB) at 60, 71 and 81 DAFB. Arrows indicate examples of the immune signal of IAA. Bars $=50 \mu \mathrm{m}$. 
5b). The vessels within the vascular tissue were lignified, but the lignification process did not occur in the phloem tissue (Fig. 5c). Corresponding to the results of the IAA immunolocalization in the endocarp, there was no signal in the vessel. However there was a strong signal located in the phloem tissue within the vascular tissue (Fig. 4a). This result showed that auxin is not related to lignification of vessels, nor does it play the role in a negative regulation of lignification.

Compared with the seed, IAA signal in the mesocarp tissue was weakly detected throughout the whole growth period. In the earlier stages of development (before 51 DAFB),

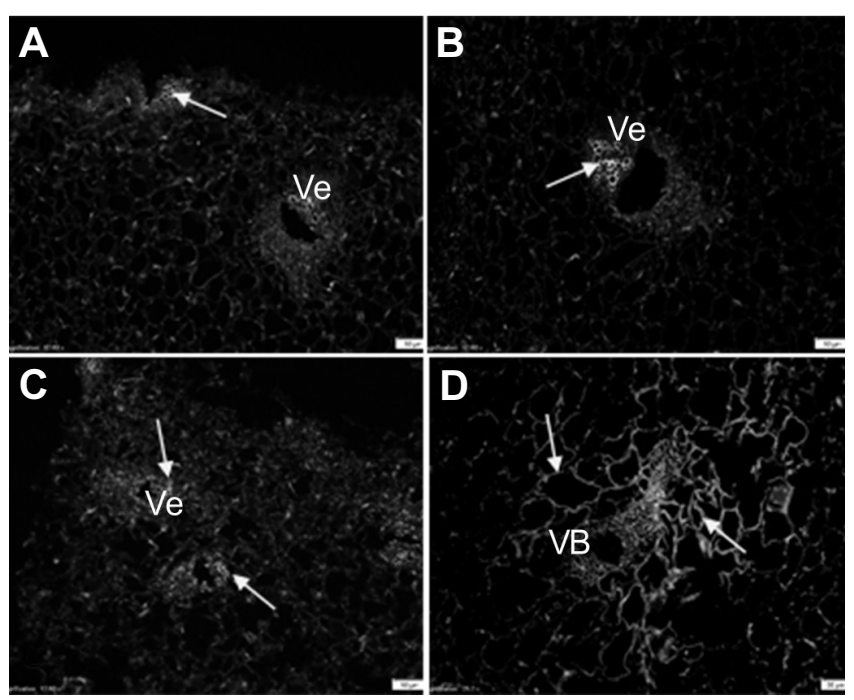

Fig. 7. Immunohistochemical localization of IAA in the mesocarp of peach ('Luwangxian') fruit treated with TIBA or NPA. $(a, b)$ IAA signal in the vessels of the mesocarp of fruit treated with TIBA. (c) Distribution of the IAA signal in the vessels of the mesocarp of fruit treated with NPA. (d) IAA signal in the parenchyma cells surrounding the vascular bundle (VB) in control fruit treated with distilled water. Bars $=50 \mu \mathrm{m}(\mathrm{a}, \mathrm{b}, \mathrm{c})$ and $20 \mu \mathrm{m}(\mathrm{d})$. there was little IAA signal (Figs. 6 a-c); however, a little strong IAA signal was detected in the parenchyma cells around the vascular bundle at 60, 71, and 81 DAFB (Figs. $6 \mathrm{~d}$-f); The signal distribution was mainly concentrated in the outer layer of cells, near the cell wall, where it differed from the IAA signal in the seeds.

\section{Effect of NPA or TIBA treatment on IAA distribution in mesocarp of peach fruit}

TIBA and NPA, inhibitors of auxin transport by combining with a carrier protein that is responsible for IAA transport, could change the protein conformation or inhibit the specific binding to repress the polar transport of IAA. No changes in IAA distribution occurred in the endocarp or seed after the fruit treated with exogenous NPA or TIBA, but in the mesocarp, IAA distribution was dramatically altered. In the control (Fig. 7d), the IAA signal was located in the parenchyma cells surrounding the vascular tissues, as seen in Figure 6, but IAA signals were present in vessels after the fruit had been treated with TIBA (Figs. 7a, b) or NPA (Fig. 7c).

\section{Verification of immunohistochemical localization technique for IAA distribution}

In order to verify the reliability of the immunolocalization technique, two controls of each tissue were carried out. The first control was the primary IAA antibody substituted by non-immune goat serum, and the second control was the primary IAA antibody omitted. The IAA distribution of the first negative controls in different tissues is shown in Figure 8. There was little IAA signal detected in these sections, indicating that the method was reliable and that the antibody was highly specific (Figs. 8 a-c).

\section{Discussion}

Auxin is one of the important phytohormones involved
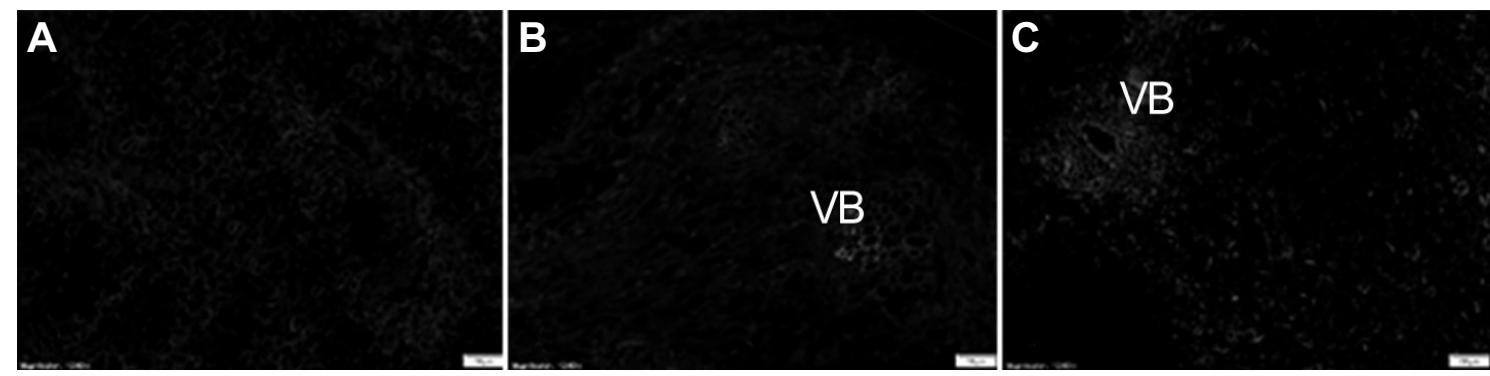

Fig. 8. Controls for the immunohistochemical localization of IAA shown in the sections of different tissues of peach ('Luwangxian') fruit. Non-immune goat serum was substituted for the IAA antibody to test the specificity of antibody. Little signal was detected in the distal part of the seed coat (a), endocarp (b) and mesocarp (c). Bars $=50 \mu \mathrm{m}$. 
in regulating the development of peach fruit. IAA is a natural auxin in plants. We measured the level of IAA in peach fruit and found that the content of IAA was different in various tissues throughout the development. Miller (1987) showed that the level of IAA decreased with the growth of the embryo from 67 DAFB to 88 DAFB. Regardless of whether an enzyme immunoassay or mass spectrometry method was used, the distribution of auxin will be destroyed during the extraction process. Therefore, an immunohistochemical localization technique was used to explore in situ auxin distribution, which would be an important step towards clarifying the regulatory mechanism of auxin in peach fruit development.

\section{Seed coat as the potential source of auxin biosynthesis}

The study of IAA determination early in fruit development shows a specificity of the developmental stages in peach fruit (Miller et al., 1987). During fruit growth, the IAA content differed among different tissues. For the same growth periods, the IAA level was the highest in the seed, followed by endocarp and mesocarp. These results are consistent with our results determined by the immunohistochemical localization of IAA technique: The content of IAA was highest in seed, whereas it was low in mesocarp and endocarp tissues.

Bonghi et al. (2011) determined that peach embryogenesis and fruit development are tightly coupled. Moreover, physiological disturbances during early embryo development will lead to seed abortion and fruitlet abscission. Different hormones affect fruit and seeds differently, and auxin will induce specific gene expression in the early and late growth periods in peach fruit (Trainotti et al., 2007). Auxin produced by the seed may behave as a signal that is efficiently transported to and within the mesocarp. Normally in plants, the embryo is the vital source of auxin production (Yoshida et al., 2012). In our study, a strong signal was accumulated in the seed coat, indicating a specific distribution of endogenous IAA. In different parts of the seed, the outer and inner integument have one or more cell layers with IAA signals (Figs. 3a, e, f, h, i). In any developmental stage, stronger IAA signals were present in the mucilage cells. It can be inferred, therefore, that the seed coat of peach fruit may be the source of auxin. In dicotyledonous plants, such as peas, auxin is made in the endosperm (Bandurski et al., 1988). The auxin content can be assayed until the endosperm is reabsorbed, so it is speculated that the embryo is not the only source of auxin.
The IAA distribution in the endocarp was consistent with the lignification

There was a difference in IAA distribution between the mesocarp and endocarp in untreated fruit. The IAA signal was detected in the phloem of vascular tissues (Fig. 4). It has been previously reported that the vascular tissue in the endocarp of peach fruit belongs to collateral vascular bundles (Zhang et al., 2009). The IAA signal was located in the phloem tissue of vascular bundles in our research. The IAA signal in the endocarp is transported through the vascular tissue, but whether it comes from the seed coat or mesocarp was unknown. The results obtained by the phloroglucinol-stain technique showed that the vessels within the vascular tissue had lignified at the second stage of fruit development, but the lignification had not occurred in the parenchyma cells around the vascular tissue. At 28 DAFB, a strong IAA signal may have existed in parenchyma cells of vascular tissue to promote the vascular differentiation and formation, and the IAA signal did not appear in the vessels. Several studies confirmed that IAA was a negative regulator of lignin synthesis (Elobeid et al., 2012). Therefore, a weak IAA signal in the vessel is consistent with the physiological phenomenon of lignin synthesis.

\section{IAA in the mesocarp may be derived from external transport}

Several studies have addressed the role of auxin in plant and fruit development (Trainotti et al., 2007; Vanneste and Friml, 2009). These data indicate that an accumulation of IAA in the vascular bundles of the basal regions of the petioles induces the occurrence of rhizogenesis of poplar leaves (Dong et al., 2012). IAA plays a crucial role in fruit development and rhizogenesis and is transported by the vascular bundle to other tissues. Ruegger et al. (1997) proposed that continuous auxin transport is necessary for the formation of vascular bundles. Sieburth (1999) indicated that the auxin is important for the induction of vascular tissue development in Arabidopsis. Our results in peach did not correspond with the results of the previous studies. In our study, there was only a weak IAA signal detected in the vascular tissues, but in the cells around the vascular tissue there appeared strong IAA signals. Stronger IAA signals were located in the seed (Fig. 3). Bonghi (2011) determined that during peach fruit development, auxin is transported from the seed to other organs by the apoplastic pathway, which was coincided with our results that IAA was produced in the seed coat, but it was not transported symplastically, indicating that it was likely translocated through the apoplastic pathway. 
Contradictory with our results, a previous study of the immunohistochemical localization of IAA was carried out in strawberry, which showed that the IAA signal spread all over the vascular tissues of the phloem (Hou and Huang, 2004). In the mescoap of peach (Fig. 6), a strong IAA signal was observed in the parenchyma cells surrounding the vascular tissue, but only a weak IAA signal was detected in the vascular tissue. This suggests that the mesocarp could produce IAA or depend on its transportation from other organs. At the later stages of fruit development, the IAA located in the parenchyma cells around vascular tissue might have been used to promote cell enlargement and mesocarp ripening. After the fruit had been treated with auxin transport inhibitors, however, the distribution of IAA within the mesocarp was switched: The IAA signal appeared in the vessels, a weak IAA signal was detected in the parenchyma cells, (Fig. 7). Treatment with TIBA or NPA would affect the normal transport of IAA, and an IAA signal could not be detected in the parenchyma cells surrounding vascular tissue after treatment. Consequently, the IAA within the parenchyma cells might be transported from other tissues in the mesocarp of normal fruit. It was interesting that the IAA signal was detected in the vessels in the mesocarp of treated fruit. As mentioned, the IAA within the seed might be transported out by apoplastic pathway, so IAA in the vessels might be transported from the endocarp while fruits were treated with TIBA or NPA.

\section{Conclusion}

The immunohistochemical analysis of IAA in peach fruit showed that the source of IAA in various fruit tissues was different. IAA was mainly derived from seed coat. In the endocarp, IAA was transported possibly through vascular tissue. In the mesocarp, IAA might come from seed coat, endocarp or other tissues, for instance, stem or leaves. Auxin differentially regulated peach development in various tissues, but the different modes of action might be consistent with their developmental characteristics. In future studies, we will assess different tissues of fruit to elucidate the role of IAA and its molecular mechanism in peach fruit development.

\section{Literature Cited}

Abeles, F.B. and C.L. Biles. 1991. Characterization of peroxidases in lignifying peach fruit endocarp. Plant Physiol. 95:269-273.

Bandurski, R.S., A. Schulze, A. Leznicki, D. Reinecke, P. Jensen, M. Desrosiers, and B. Epel. 1988. Regulation of the amount of IAA in seedling plants, p. 21-32. In: Kutacek M, R.S. Bandurski, and J. Krekule, (eds) Physiology and biochemistry of auxins in plants. Academia, Prague.

Bonghi, C., L. Trainotti, A. Botton, A. Tadiello, A. Rasori, F. Ziliotto, V. Zaffalon, G. Casadoro, and A. Ramina. 2011. A microarray approach to identify genes involved in seed-pericarp cross-talk and development in peach. BMC Plant Biol. 11:107.

Chen, D., Y. Ren, Y. Deng, and J. Zhao. 2010. Auxin polar transport is essential for the development of zygote and embryo in Nicotiana tabacum L. and correlated with ABP1 and PM $\mathrm{H}^{+}$-ATPase activities. J. Exp. Bot. 61:1853-1867.

Dong, N.G., D. Pei, and W.L. Yin. 2012. Tissue-specific localization and dynamic changes of endogenous IAA during poplar leaf rhizogenesis revealed by in situ immunohistochemistry. Plant Biotechnol. Rep. 6:165-174.

Elobeid, M., C. Göbel, L. Feussner, and A. Polle. 2012. Cadmium interferes with auxin physiology and lignification in polar. J. Exp. Bot. 63:1413-1421.

Goetz, M., L.C. Hooper, S.D. Johnson, J.C.M. Rodrigues, A. Vivian-Smit, and A.M. Koltunow. 2007. Expression of aberrant forms of AUXIN RESPONSE FACTOR8 stimulates parthenocarpy in Arabidopsis and tomato. Plant Physiol. 145:351-366.

Hou, Z.X. and W.D. Huang. 2005. Immunohistochemical localization of IAA and ABP1 in strawberry shoot apexes during floral induction. Planta 222:678-687.

Hou, Z.X. and W.D. Huang. 2004. Immunochemical localization of IAA and ABP1 in development Strawberry fruit. J. Hort. Sci. Biotechnol. 79: 693-698.

Kalluri, U.C., M.M. Basu, S.S. Jawdy, and G.A. Tuskan. 2011. Auxin signaling and response mechanisms and roles in plant growth and development. Genetics, Genomics and Breeding of Poplar, p 231-254.

Liu, D.J., J.Y. Chen, and W.J. Lu. 2011. Expression and regulation of the early auxin-responsive Aux/IAA genes during strawberry fruit development, Mol. Biol. Rep. 38:1187-1193.

Liu, S.C., W.Q. Chen, L. Qu, Y. Gai, and X.N. Jiang. 2013. Simultaneous determination of 24 or more acidic and alkaline phytohormones in femtomole quantities of plant tissues by high-performance liquid chromatography-electrospray ionizationion trap mass spectrometry. Anal. Bioanul. Chem. 405:1257-1266.

Miller, A.N., C.S. Walsh, and J.D. Cohen. 1987. Measurement of indole-3-acetic acid in peach fruits (Prumus persica L. Batsch cv.Redhaven) during development. Plant Physiol. 84:491-494.

Molesini, B., T. Pandolfini, G.L. Rotino, V. Dani, and A. Spena. 2009. Aucsia gene silencing causes parthenocarpic fruit development in tomato. Plant Physiol. 149:534-548.

Mounet, F., A. Moing, V. Garcia, J. Petit, M. Maucourt, C. Deborde, S. Bernillon, G. Le Gall, I. Colquhoun, M. Defernez, J.L. Giraudel, D. Rolin, C. Rothan, and M. Lemaire-Chamley. 2009. Gene and metabolite regulatory network analysis of early developing fruit tissues highlights new candidate genes for the control of tomato fruit composition and development. Plant 
Physiol. 149:1505-1528.

Paponov, I.A., W.D. Tea, M. Trebar, I. Blilou, and K. Palme. 2005. The PIN auxin efflux facilitators: evolutionary and functional perspectives. Trends Plant Sci. 10: 170-177.

Petrášek, J., K. Malínská, and E. Zažímalová. 2011. Auxin Transporters Controlling Plant Development, p. 255-290. In: Transporters and Pumps in Plant Signaling. Springer Berlin Heidelberg.

Ruegger, M., E. Dewey, L. Hobbie, D. Brown, P. Bernasconi, J. Turner, G. Muday, and M. Estelle. 1997. Reduced naphthylphthalamic acid binding in the tir3 mutant of Arabidopsis is associated with a reduction in polar auxin transport and diverse morphological defects. Plant Cell 9:745-757.

Sieburth, L.E. 1999. Auxin is required for leaf vein pattern in Arabidopsis. Plant Physiol. 121:1179-1190.

Thomas, C., R. Bronner, J. Molinier, E. Prinsen, H. Van Onckelen, and G. Hahne. 2002. Immunocytochemical localization of indole-3-acetic acid during induction of somatic embryogenesis in cultured sunflower embryos. Planta 215:577-583

Torrigiani, P., D. Bressanin, K.B. Ruiz, A. Tadiello, L.Trainotti, C. Bonghi, V. Ziosi, and G. Costa. 2012. Spermidine application to young developing peach fruits leads to a slowing down of ripening by impairing ripening-related ethylene and auxin metabolism and signaling. Physiol. Plant 146:86-98.

Trainotti, L., A. Tadiello, and G. Casadoro. 2007. The involvement of auxin in the ripening of climacteric fruits comes of age: the hormone plays a role of its own and has an intense interplay with ethylene in ripening peaches. J. Exp. Bot. 58:3299-3308.

Vanneste, S. and J. Friml. 2009. Auxin: A trigger for change in plant development. Cell 136:1005-1016.

Verde, I., A. Abbott, S. Simone, et al. 2013. The high-quality draft genome of peach (Prunus persica) identifies unique patterns of genetic diversity, domestication and genome evolution. Nat. Genet. 45:487-494. Pages:

Wang, H., B. Jones, Z.G. Li, P. Frasse, C. Delalande, F. Regad, S. Chaabouni, A. Latche, J.C. Pech, and M. Bouzaven. 2005. The tomato Aux/IAA transcription factor IAA9 is involved in fruit development and leaf morphogenesis. The Plant Cell 17: 2676-2692.

Yoshida, S., S. Saiga, and D. Weijers. 2012. Auxin regulation of embryonic root formation. Plant Cell Physiol. 54:325-336.

Zhang, J., Z.M. Liu, H.P. Ma and S.P. Ma. 2009. Studies on anatomy and distribution of the vascular bundles in the peach fruit. Acta Hortic. Sin. 36:639-646. (in Chinese) 